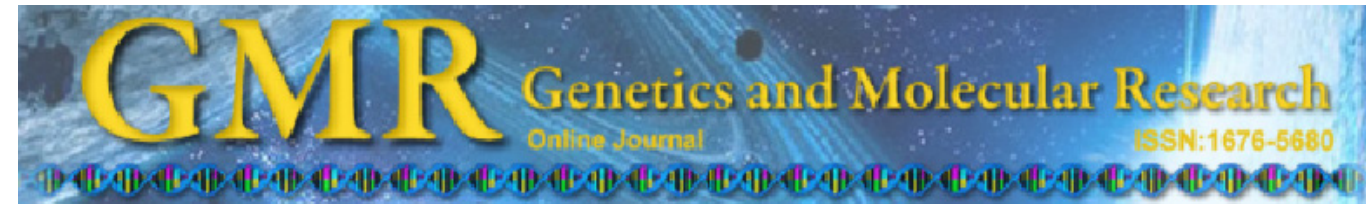

\title{
Association of neuropeptide $Y$ and gonadotrophin-releasing hormone receptor gene SNPs with breeding value for growth and egg production traits in Mazandaran native chickens
}

\author{
S.A. Fatemi, H. Mehrabani-Yeganeh, A. Nejati-Javaremi and Sh. Niknafs \\ Department of Animal Science, \\ University College of Agricultural and Natural Resources, \\ University of Tehran, Karaj, Iran \\ Corresponding author: Sh. Niknafs \\ E-mail: niknafssh@gmail.com
}

Genet. Mol. Res. 11 (3): 2539-2547 (2012)

Received October 21, 2011

Accepted March 26, 2012

Published July 10, 2012

DOI http://dx.doi.org/10.4238/2012.July.10.9

\begin{abstract}
Neuropeptide Y (NPY) and gonadotrophin-releasing hormone receptor (GnRHR) are two candidate genes with a wide variety of physiological functions in growth and especially in reproduction processes. We examined the association of one SNP from each of these genes with growth- and egg production-related traits in Mazandaran native chickens. Two hundred and six individuals were genotyped by PCR-RFLP. Marker-trait association analyses were performed using both breeding value and phenotypic information. The data came from 18 successive generations of selection at a Mazandaran native chicken breeding station in Iran. Data were analyzed with a univariate animal model in an ASREML procedure to estimate breeding values of the birds for these traits. Two alleles were found for both genes, A and a alleles for GnRHR, with frequencies of 0.614 and $0.386, \mathrm{~B}$ and $\mathrm{b}$ alleles for NPY, with frequencies of 0.780 and 0.221 , respectively.
\end{abstract}


The additive genetic effects of the GnRHR gene on egg number and egg mass were significant. Also, body weight at sexual maturity was significantly influenced by the NPY gene. We conclude that GnRHR and NPY genes are associated with egg production and growth traits, respectively.

Key words: Breeding value; Candidate gene; Chicken; Economic trait; Single nucleotide polymorphism

\section{INTRODUCTION}

More than $80 \%$ of the world poultry population is in village production systems, contributing up to $90 \%$ of poultry products in some developing countries (Gueye, 1998). In some developing countries, native stocks may reach up to 90 percent of the poultry population (Pym et al., 2006). A national project for increasing the number of native poultry breeds was started in Iran in 1983. In this project, various native breeds were reared in 14 poultry centers in different parts of the country and the vaccinated pullets distributed to the villagers. The project increased the number of native poultry, which was about 52 million pieces in the year 2006 (in contrast to 16 million pieces in 1982) (Kamalzadeh et al., 2008). Among the native chicken breeding stations in Iran, the Mazandaran breeding station, located in the north, has been debuted in 1988 with two main objectives, namely extension and genetic improvement. Genetic improvement is done by selecting the best 100 cocks and 800 hens as parents of the next generations (Kamalzadeh et al., 2008). Meanwhile, 8-week-old chicks are distributed among rural communities with the aim of increasing the population of native fowls in northern provinces of Iran.

Gonadotrophin-releasing hormone receptors (GnRHRs) are mainly associated with the development and function of the reproductive axis in avian species (Bedecarrats et al., 2006). The rapid decrease in ovarian activity in broiler breeders after the start of laying is a consequence of decreased gonadotrophin secretion (Sharp et al., 1992), resulting from decreased secretion of GnRH. It acts by binding to specific GnRH receptors on the membrane of pituitary gonadotropes, where it stimulates the synthesis and release of luteinizing hormone (LH) and follicle-stimulating hormone (FSH) (Hattori et al, 1986; Pawson and McNeilly, 2005). An additive genetic effect of the GnRHR gene on the number of double-yolk eggs has been found (Dunn et al., 2004). GnRH and its receptor start the cascade that produces the appropriate growth, maturation and maintenance of the gonads (Dunn et al., 2004).

An important neuromodulator affecting gonadal function in mammals and birds is neuropeptide Y (NPY) (Hilal et al., 1996). In broilers, NPY stimulates feeding and insulin secretion when injected into the brain (Kuenzel et al, 1987; Kuenzel and McMurtry, 1988). Injections of NPY change the plasma concentration of luteinizing hormone, growth hormone (Pierroz et al., 1996), prolactin, thyrotropin, GnRH, ACTH, and vasopressin (Willoughby and Blessing, 1987), suggesting that it may play significant roles in the secretion of these hormones (Wang et al., 2001). NPY can be considered as one of candidates for a neuromodulatory link between nutrition and reproduction at the level of the CNS (Wójcik- 
Gładysz and Polkowska, 2006). Some genetic markers in the NPY gene may be associated with age at first egg. Also, NPY may affect egg production rate through its role in the control of ovulation (Dunn et al., 2004). The close association of NPY and GnRH perikarya and fibers in the chick brain suggests a functional interaction between the two peptides in regulating gonadal function (Kuenzel, 2000). NPY is known to influence the release of GnRH from the median eminence (Contijoch et al., 1993). The objective of the current study was to investigate the polymorphism of GnRHR and NPY genes and their possible additive genetic effects on growth and egg production traits.

\section{MATERIAL AND METHODS}

\section{Experimental population}

In 1986, about 5000 cocks and hens were purchased from rural regions across the Mazandaran province and kept on a quarantine farm for a year. In 1987, about 2500 birds of both sexes were kept to produce hatching eggs, and chicks produced from these eggs were transferred to the station in 1988. Since then, birds have been individually tagged, and a trap nest has been used for pedigree recording. Genetic evaluation of the birds for body weight at 8 weeks, age of the hens at first egg, average egg weight and total number of eggs laid during first 12 weeks after flock's maturity (when $5 \%$ of the flock are in egg production) was performed. Economic indices were calculated for these traits, and birds of both sexes were selected based on their aggregate genotypes for these traits (Khadem et al., 2010). Parents of each generation (100 cocks and 800 hens) were selected among 6000 pedigreed animals (Enayati and Rahimi-Mianji, 2009). A total of 206 individuals from Mazandaran Native Chicken, including 10 males and 196 females that were reared in the native chicken breeding station of Mazandaran, were randomly selected. The individuals belonged to generation 17 of the breeding station's pedigreed animals, which were developed by crossing 80 sires and 751 dams from generation 16.

\section{Traits measured}

Whole information data file (18 successive generations) consisted of three registered fixed effect factors (generation, sex and hatch) and 11 recorded traits including body weight at hatch (bw1), body weight at age of 8 (bw8) and 12 (bw12) weeks, body weight at sexual maturity (wsm), age at sexual maturity (asm), egg number (en), first egg weight (ew1), average egg weight at age of 28 (ew28), 30 (ew30) and 32 (ew32) weeks, and average egg weight for the first 12 weeks of production (ew12). Bw1, bw 8 and bw12 were measured in both male and female chickens. The traits bw1, ew28, ew30 and ew32 were recorded since generation 9 in the breeding station. There was also no information for the bw 12 and ew 1 traits in the primary 4 generations. Moreover, three combined traits consisting of av (average of ew28, ew30 and ew32), intensity of egg production [eint $=($ egg number/days recorded $) \times 100]$ and egg mass $(e m=e n \times e w 12)$ were determined and $(c o)$ variance components were also estimated for them. A description of the data set is shown in Table 1. 
Table 1. Primers used for amplification of the genes (Dunn et al., 2004).

\begin{tabular}{lll}
\hline Gene & Primer sequence & SNP \\
\hline GnRHR & Forward: 5'-GGTGTCTGAGGCTCATTTCA-3' & Bases 282-301, AJ506779 \\
& Reverse: 5'-TAGCAATCGCTTGCCCAGA-3' & Bases 682-700, AJ506779 \\
NPY & Forward: 5'-TCTCAGAGCTCCAACGTATGA-3' & Bases 415-435, M87298 \\
& Reverse: 5'-ATATTTCTGTGCCTGAACAACA-3' & Bases 645-666, M87298 \\
\hline
\end{tabular}

$\mathrm{SNP}=$ single nucleotide polymorphism.

\section{Establishment of a PCR-RFLP assay}

Blood was sampled from plumage veins and was stored in tubes containing EDTA as an anticoagulant. DNA was isolated by a slightly modified standard salting out procedure described by Miller et al. (1988). Fragments of 400 and 250 bp of the GnRHR and NPY genes, respectively, were amplified by polymerase chain reaction (PCR) in a total of $25 \mu \mathrm{L}$, which included $1 \mu \mathrm{L}$ pooled DNA, $1 \mu \mathrm{L}$ each primer $(10 \mu \mathrm{M}), 0.5 \mu \mathrm{L}$ dNTPS $(10 \mathrm{mM}), 2.5 \mu \mathrm{L} 10 \mathrm{X}$ PCR buffer, and $1 \mathrm{U}$ TaqDNA polymerase, using special primers (Table 1). Cycles applied were: initial denaturation at $94^{\circ} \mathrm{C}$ for $5 \mathrm{~min} ; 30$ cycles consisting of $60 \mathrm{~s}$ at $94^{\circ} \mathrm{C}, 60 \mathrm{~s}$ at $59.7^{\circ} \mathrm{C}$ and $60 \mathrm{~s}$ at $72^{\circ} \mathrm{C}$ for denaturation, annealing and extension steps, respectively; and a final extension at $72^{\circ} \mathrm{C}$ for $7 \mathrm{~min}$. PCR products of the GnRHR and NPY genes were digested by $1 \mu \mathrm{L} B p u 1102 \mathrm{I}$ and DarI enzymes, respectively, and electrophoresed on a $2 \%$ agarose gel stained with ethidium bromide.

\section{Statistical analyses}

Pedigree and data file were prepared using the Visual FoxPro 9.0 software, the relational database management system. The SAS 9.1 package was used to carry out descriptive statistics and fitting model. Fixed effect factors and their interactions were considered in the animal model utilized, providing there was a significant effect. Genetic analyses were performed using the ASREML software (Gilmour et al., 2006). Breeding values of growth and egg production traits were estimated using a univariate animal model. The models used in matrix notation were as follows:

$$
y=X b+Z a+e
$$

(Equation 1)

where $y=$ vector of observations; $b=$ vector of fixed effects of generation, sex and hatch; $a=$ vector of random direct genetic effects; $e=$ vector of random residual effects, and $X$ and $Z$ are incidence matrices relating the observations to the respective fixed and direct genetic effects.

Allele and genotype frequencies of the SNPs were calculated and the chi-square test was performed to test for Hardy-Weinberg equilibrium. Marker-trait association analyses were conducted using the two following models including breeding values and phenotypic information separately in the GLM procedure of SAS 9.1. The significant differences of least squares means were performed by the Tukey-Kramer multiple range test, and a $P$ value of $\leq 0.05$ was considered to be statistically significant.

$$
\mathrm{Y}_{\mathrm{ijk}}=\mu+\mathrm{G}_{\mathrm{i}}+\mathrm{N}_{\mathrm{j}}+\mathrm{e}_{\mathrm{ijk}}
$$

(Equation 2) 
where $Y_{i j k}=$ estimated breeding values of traits, $\mu$ = population mean, $G_{i}=$ fix effect of GnRHR genotypes, $N_{i}=$ fix effect of NPY genotypes, $e_{i j k}=$ residual random error. There was no significant interaction between the genes' additive effects.

$$
Y_{i j k l m}=\mu+\operatorname{Sex}_{i}+H_{j}+G_{k}+N_{l}+e_{i j k l m}
$$

where $Y_{i j k l m}=$ phenotypic observations, $\mu$ = population mean, $S e x_{i}=$ fix effect of sex, $H_{j}=$ fix effect of hatch, $G_{k}=$ fix effect of GnRHR genotypes, $N_{l}=$ fix effect of NPY genotypes, $e_{i j k l m}=$ residual random error.

\section{RESULTS}

\section{Genotyping and frequencies}

The GnRHR and NPY genes were genotyped after digestion of the PCR products with the restriction enzymes Bpu1102I and DarI, respectively. The restriction fragment lengths for the $\mathrm{A}$ and a alleles of the GnRHR gene were 255/145 and $400 \mathrm{bp}$, and for the B and b alleles of the NPY gene 240 and 79/161 bp, respectively. Genotype and allele frequencies for both genes investigated are shown in Table 2.

\begin{tabular}{|c|c|c|c|c|}
\hline Gene & Genotype & Frequency & Allele & Frequency \\
\hline \multirow[t]{2}{*}{ GnRHR } & $\begin{array}{l}\text { AA } \\
\text { Aa }\end{array}$ & $\begin{array}{l}0.379 \\
0.469\end{array}$ & A & 0.614 \\
\hline & aa & 0.152 & $\mathrm{a}$ & 0.386 \\
\hline \multirow[t]{3}{*}{ NPY } & BB & 0.664 & B & 0.780 \\
\hline & $\mathrm{Bb}$ & 0.231 & & \\
\hline & $\mathrm{bb}$ & 0.105 & $\mathrm{~b}$ & 0.221 \\
\hline
\end{tabular}

\section{Marker-trait association}

Statistical description of data set and pedigree information are presented in Tables 3 and 4 , respectively. Table 5 presents the results of the association analyses using both breeding values and phenotypic information of growth- and egg production-related traits in least squares means.

Table 3. Statistical description of data set for growth and egg production traits.

\begin{tabular}{lccr}
\hline Trait & No. of animals in data file & Mean & Coefficient of variation \\
\hline bw1 (g) & 35,287 & 35.53 & 8.15 \\
bw8 (g) & 43,067 & 563.7 & 17.09 \\
bw12 (g) & 38,297 & 953.9 & 14.49 \\
wsm (g) & 31,147 & 11.90 \\
asm (days) & 31,349 & 9.23 \\
en (No.) & 31,349 & 165.5 & 39.78 \\
ew1 (g) & 27,294 & 36.66 & 15.74 \\
ew28 (g) & 17,225 & 41.21 & 8.48 \\
ew30 (g) & 19,031 & 8.50 \\
ew32 (g) & 18,955 & 46.91 & 9.29 \\
ew12 (g) & 18,847 & 48.12 & 13.05 \\
av (g) & 28,725 & 49.22 & 39.89 \\
em (No. x g) & 28,725 & 46.62 & 33.29 \\
eint (No./days x 100) & 31,349 & 46.84 & 1768 \\
\hline
\end{tabular}

bw = body weight; wsm = body weight at sexual maturity; asm = age at sexual maturity; en = egg number; ew = egg weight; av = average egg weight; em = egg mass; eint = intensity of egg production. 


\begin{tabular}{lc} 
Table 4. Pedigree information. & \\
\hline Information & No. of animals \\
\hline Animals in total & 75,476 \\
Inbred animals & 57,175 \\
Sires in total & 1,615 \\
Dams in total & 11,495 \\
Progeny & 74,463 \\
Animals with progeny & 13,110 \\
Animals without progeny & 62,366 \\
Non-base animals & 74,463 \\
Base animals & 1,013 \\
\hline Generation & \\
\hline 1 & 2,031 \\
2 & 2,490 \\
3 & 2,336 \\
4 & 2,635 \\
5 & 3,935 \\
6 & 3,393 \\
7 & 3,830 \\
8 & 3,739 \\
9 & 3,723 \\
10 & 4,079 \\
11 & 3,611 \\
12 & 3,858 \\
13 & 3,721 \\
15 & 3,304 \\
16 & 2,860 \\
18 & 9,186 \\
\hline
\end{tabular}

Marker-trait association analyses using breeding values of the traits showed a significant effect of the GnRHR gene on the traits egg number and egg mass $(\mathrm{P}<0.05)$ (Table 5). In the case of the NPY gene, just LSM for body weight at sexual maturity was significantly genetically influenced by the SNP $(\mathrm{P}<0.05)$ (Table 5$)$. Nonetheless, at the phenotypic level, no significant associations were found between the genetic markers and the traits investigated (Table 5).

Table 5. Effects of GnRHR and NPY genes on growth and egg production traits.

\begin{tabular}{|c|c|c|c|c|c|c|c|}
\hline \multirow[t]{2}{*}{ Gene } & \multirow[t]{2}{*}{ Genotype } & \multicolumn{2}{|c|}{ wsm } & \multicolumn{2}{|c|}{ en } & \multicolumn{2}{|c|}{$\mathrm{em}$} \\
\hline & & PI & BV & PI & BV & PI & BV \\
\hline \multirow[t]{3}{*}{ GnRHR } & AA & $1661 \pm 55.4$ & $-20.67 \pm 16.2$ & $41.13 \pm 4.02$ & $14.16 \pm 0.33^{\mathrm{a}}$ & $2028 \pm 184.7$ & $657.6 \pm 14.5^{\mathrm{a}}$ \\
\hline & $\mathrm{Aa}$ & $1729 \pm 52.4$ & $-9.07 \pm 14.66$ & $37.69 \pm 3.80$ & $13.90 \pm 0.29^{\mathrm{ab}}$ & $1872 \pm 174.8$ & $649.8 \pm 13.1^{\mathrm{ab}}$ \\
\hline & aa & $1741 \pm 57.9$ & $-4.94 \pm 19.46$ & $34.71 \pm 4.20$ & $13.19 \pm 0.39^{\mathrm{b}}$ & $7442 \pm 192.9$ & $614.7 \pm 17.4^{\mathrm{b}}$ \\
\hline \multirow[t]{3}{*}{ NPY } & BB & $1735 \pm 18.01$ & $-17.53 \pm 7.2^{\mathrm{ab}}$ & $40.05 \pm 1.30$ & $14.2 \pm 0.14$ & $1987 \pm 60.14$ & $653.4 \pm 6.4$ \\
\hline & $\mathrm{Bb}$ & $1835 \pm 49.08$ & $29.34 \pm 19.43^{\mathrm{a}}$ & $37.14 \pm 3.56$ & $14.02 \pm 0.39$ & $1837 \pm 163.5$ & $656.6 \pm 17.37$ \\
\hline & $\mathrm{bb}$ & $1560 \pm 139.1$ & $-46.49 \pm 35.43^{b}$ & $36.34 \pm 10.09$ & $13.04 \pm 0.72$ & $1819 \pm 463.5$ & $612.1 \pm 31.6$ \\
\hline
\end{tabular}

$\mathrm{wsm}=$ body weight at sexual maturity; en = egg number; em = egg mass. PI = least squares mean of phenotypic

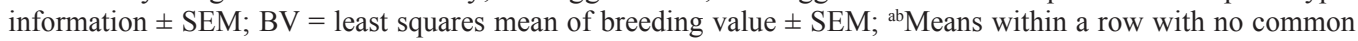
superscript letters differ significantly $(\mathrm{P}<0.05)$. 


\section{DISCUSSION}

The number of confirmed causative genes associated with traits of biomedical, economic and evolutionary importance is still small and the list of identified candidate genes is limited. However, the candidate gene approach is useful for quickly determining the association of a specific genetic variant with phenotype (Zhu and Zhao, 2007). Knowledge of markertrait associations at the farm level is necessary to perform any MAS program (Ragot and Lee, 2007). One advantage of SNPs is that they are usually linked to the gene of interest, and association of the SNP with traits of economic importance can be analyzed using candidate gene approaches (Emara and Kim, 2003).

Because of the lack of pedigree information and company's exclusivity, marker-trait association analyses using breeding value information, especially in chickens, are rare, while the application of pedigree information may lead to the detection of more accurate and reliable associations between genetic markers and traits of economic importance. In this study, in addition to phenotypic information, breeding values were also used to examine the probable effects of the one SNP from each of the GnRHR and NPY genes on growth and egg production traits in Mazandaran native chicken.

Our results suggested a significant additive genetic effect of the GnRHR gene on traits of egg number and egg mass. Chickens with genotype of AA significantly produce more eggs than other genotypes, which was followed by more egg mass production (Table 5). However, no significant differences were observed among genotypes at the phenotypic level (Table 5). Dunn et al. (2004) found a significant association between GnRHR gene and the number of double-yolk eggs in a commercial broiler breeder hen population. Dominance effect of this gene on egg number in Wenchang chicken was reported by Wu et al. (2007). GnRHs are mainly associated with the development and function of the reproductive axis in avian species (Bedecarrats et al., 2006). Also, GnRH and its receptor therefore begin the cascade that produces the appropriate growth, maturation and maintenance of the gonads (Dunn et al., 2004).

In the case of the NPY gene, egg production traits were not significantly affected by the SNPs investigated, but growth traits and body weight at sexual maturity demonstrated significant additive impressibility. However, a higher breeding value LSM was obtained for the heterozygote genotype (Table 5). Since breeding values are representative of additive genetic values, this result may indicate the existence of other effective SNPs of NPY or other highly linked genes with NPY. The effect of NPY on body weight may be expected because of its critical role in controlling feed intake (Clark et al., 1984; Billington et al., 1994; Kuenzel and Fraley, 1995) and growth hormone secretion (Pierroz et al., 1996). As with the GnRHR gene, phenotypic performances were not significantly influenced by the NPY gene. Significant dominance and additive effect of NPY gene on age at first egg and egg number was reported by Dunn et al. (2004) and Wu et al. (2007), respectively.

Interestingly, performing marker-trait association analyses exerting additive genetic effect and phenotypic performance as a dependent variable in separate statistical models produced completely discrepant results. Such differences may be due to non-additive genetic effects (dominance and epistasis), environmental effects, genetic-environmental interaction, etc.

It is worth mentioning that NPY is known to influence the release of GnRH from the median eminence (Contijoch et al., 1993; Wójcik-Gładysz and Polkowska, 2006). The close association of NPY and GnRH perikarya and fibers in these two areas of the chick brain sug- 
gests a functional interaction between the two peptides in regulating gonadal function (Tsuruo et al., 1990). Nonetheless, in the current study no significant genetic interaction was observed between the GnRHR and NPY genes.

Taken together, this study suggested significant associations of the GnRHR and NPY genes with egg production and growth traits, respectively in the Mazandaran indigenous chicken. Also, performing association analysis using breeding value and phenotypic records produced completely different results. This may indicate that in MAS programs we should be more scrupulous about candidate genes and their associations with traits.

\section{ACKNOWLEDGMENTS}

We sincerely thank the farm attendants and staff who worked on data collection and let us to provide blood samples at the breeding station of Mazandaran native chicken.

\section{REFERENCES}

Bedecarrats GY, Shimizu M and Guemene D (2006). Gonadotropin releasing hormones and their receptors in avian species. Poult. Sci. 43: 199-214.

Billington CJ, Briggs JE, Harker S and Grace M (1994). Neuropeptide Y in hypothalamic paraventricular nucleus: a center coordinating energy metabolism. Am. J. Physiol. 266: 1765-1770.

Clark JT, Kalra PS, Crowley WR and Kalra SP (1984). Neuropeptide Y and human pancreatic polypeptide stimulate feeding behavior in rats. Endo 115: 427-429.

Contijoch AM, Malamed S, McDonald JK and Advis JP (1993). Neuropeptide Y regulation of LHRH release in the median eminence: immunocytochemical and physiological evidence in hens. Neuroendocrinology 57: 135-145.

Dunn IC, Miao YW, Morris A, Romanov MN, et al. (2004). A study of association between genetic markers in candidate genes and reproductive traits in one generation of a commercial broiler breeder hen population. Heredity 92: 128-134.

Emara MG and Kim H (2003). Genetic markers and their application in poultry breeding. Poult. Sci. 82: 952-957.

Enayati B and Rahimi-Mianji G (2009). Genomic growth hormone, growth hormone receptor and transforming growth facor $\beta$-3 gene polymorphism in breeder hens of Mazandaran native fowls. Afr. J. Biotechnol. 8: 3154-3159.

Gilmour AR, Gogel BJ, Cullis BR and Thompson R (2006). ASReml User Guide. NSW Department of Primary Industries, Australia.

Gueye EHF (1998). Village egg and fowl meat production in Africa. World Poult. Sci. J. 54: 73-86.

Hattori A, Ishii S and Wada M (1986). Effects of two kinds of chicken luteinizing hormone-releasing hormone (LHRH), mammalian LH-RH and its analogs on the release of LH and FSH in Japanese quail and chicken. Gen. Comp. Endocrinol. 64: 446-455.

Hilal EM, Chen JH and Silverman AJ (1996). Joint migration of gonadotropin-releasing hormone (GnRH) and neuropeptide Y (NPY) neurons from olfactory placode to central nervous system. J. Neurobiol. 31: 487-502.

Kamalzadeh A, Rajabbaigy M and Kiasat A (2008). Livestock production systems and trends in livestock industry in Iran. J. Agr. Soc. Sci. 4: 183-188.

Khadem A, Hafezian H and Rahimi-Mianji G (2010). Association of single nucleotide polymorphisms in IGFI, IGF-II and IGFBP-II with production traits in breeder hens of Mazandaran native fowls breeding station. Afr. J. Biotechnol. 9: 805-810.

Kuenzel WJ (2000). Central nervous system regulation of gonadal development in the avian male. Poult. Sci. 79: 16791688.

Kuenzel WJ and McMurtry J (1988). Neuropeptide Y: brain localization and central effects on plasma insulin levels in chicks. Physiol. Behav. 44: 669-678.

Kuenzel WJ and Fraley GS (1995). Neuropeptide Y its role in the neural regulation of reproductive function and food intake in avian and mammalian species. Poult. Avian Biol. Rev. 6: 185-209.

Kuenzel WJ, Douglass LW and Davison BA (1987). Robust feeding following central administration of neuropeptide Y or peptide YY in chicks, Gallus domesticus. Peptides 8: 823-828.

Miller SA, Dykes DD and Polesky HF (1988). A simple salting out procedure for extracting DNA from human nucleated cells. Nucleic Acids Res. 16: 1215. 
Pawson AJ and McNeilly AS (2005). The pituitary effects of GnRH. Anim. Reprod. Sci. 88: 75-94.

Pierroz DD, Catzeflis C, Aebi AC, Rivier JE, et al. (1996). Chronic administration of neuropeptide Y into the lateral ventricle inhibits both the pituitary-testicular axis and growth hormone and insulin-like growth factor I secretion in intact adult male rats. Endocrinology 137: 3-12.

Pym RAE, Guerne Bleich E and Hoffmann I (2006). The Relative Contribution of Indigenous Chicken Breeds to Poultry Meat and Egg Production and Consumption in the Developing Countries of Africa and Asia. Proceedings of the 7th European Poultry Conference, Verona.

Ragot M and Lee M (2007). Marker-assisted Selection in Maize: Current Status, Potential, Limitations and Perspectives from the Private and Public Sectors. In: Marker-assisted Selection: Current Status and Future Perspectives in Crops Livestock Forestry and Fish (Guimarães EP, Ruane J, Scherf BD, Sonnino A, et al., eds.). Food and Agriculture Organization of the United Nations, Rome, 117-150.

Sharp PJ, Dunn IC and Cerolini S (1992). Neuroendocrine control of reduced persistence of egg-laying in domestic hens: evidence for the development of photorefractoriness. J. Reprod. Fertil. 94: 221-235.

Tsuruo Y, Kawano H, Kagotani Y, Hisano S, et al. (1990). Morphological evidence for neuronal regulation of luteinizing hormone-releasing hormone-containing neurons by neuropeptide $\mathrm{Y}$ in the rat septo-preoptic area. Neurosci. Lett. 110: 261-266.

Wang X, Day JR and Vasilatos-Younken R (2001). The distribution of neuropeptide Y gene expression in the chicken brain. Mol. Cell Endocrinol. 174: 129-136.

Willoughby JO and Blessing WW (1987). Neuropeptide Y injected into the supraoptic nucleus causes secretion of vasopressin in the unanesthetized rat. Neurosci. Lett. 75: 17-22.

Wójcik-Gładysz A and Polkowska J (2006). Neuropeptide Y-a neuromodulatory link between nutrition and reproduction at the central nervous system level. Reprod. Biol. 6 (Suppl 2): 21-28.

Wu X, Li HF, Yan MG and Tang QP (2007). Association of gonadotropin-releasing hormone receptore (GnRHR) and neuropeptide y (NPY) genes polymorphisms with egg-laying traits in Wenchang chicken. Agr. Sci. China 6: 499-504.

Zhu M and Zhao S (2007). Candidate gene identification approach: progress and challenges. Int. J. Biol. Sci. 3: 420-427. 